\title{
Grain Growth Anomaly in Ti-rich Strontium Titanate as Revealed by Electron Microscopy
}

\author{
L. Amaral*, M. Fernandes*, A. M. R. Senos*, P. M. Vilarinho*, and M. P. Harmer** \\ * Department of Ceramics and Glass Engineering, CICECO, University of Aveiro, 3810-193 Aveiro, \\ Portugal \\ ** Center for Advanced Materials and Nanotechnology, Lehigh University, Bethlehem, PA 18015, \\ USA
}

An anomaly in the dependence of the kinetics of grain growth on the temperature for strontium titanate (ST) ceramics is reported in this work. It consists of a decrease of the grain size with increasing sintering temperature. Recently, a drop in the grain boundary mobility of ST in the same temperature range was reported [1]. These observations imply an unusual decrease of the grain size with the increase of the sintering temperature, in agreement with our present results. Although the mobility drop was related to structural changes in grain boundaries, the exact mechanism involved is still unknown. The understanding of this anomaly may offer an alternative way of controlling the microstructure and tuning the dielectric response of ST based compositions without the use of dopants. ST is characterized by high dielectric permittivity, high tunability and low dielectric losses, and is thus a particularly interesting material for capacitor or tunable microwave devices. These properties are very dependent on the stoichiometry, structure and microstructure, in which the role of grain boundaries is fundamentally important. Indeed, increasing attention has been paid to grain boundary structures [2,3] and nonstoichiometry [3-5] and to its relation with microstructure and electrical properties. Densification proceeds faster with decreasing $\mathrm{Sr} / \mathrm{Ti}$ ratio (Ti-rich compositions). Sr-rich samples show narrow grain size distributions, while Ti excess favors enlarged grain size distributions and faceting of the grain boundaries [3-5].

In this work, the microstructures of a Ti-rich $(\mathrm{Sr} / \mathrm{Ti}$ ratio=0.995) strontium titanate composition (ST 0.995) prepared by the conventional mixed oxide method and sintered for $2 \mathrm{~h}$ at temperatures between 1400 and $1500^{\circ} \mathrm{C}$ were assessed in detail by scanning and transmission electron microscopy (SEM and TEM). From the XRD point of view, the starting nonstoichiometric powders are monophasic. Coarse microstructures (Fig.1) and enlarged grain size distributions were observed for all samples, which reached relative densities higher than $98 \%$. The residual porosity consists mainly of small and rounded intragranular pores. As depicted in Fig. 1 (d), with the increase of the sintering temperature from $1400^{\circ} \mathrm{C}$ to $1450^{\circ} \mathrm{C}$ an increase of the grain size was observed, as expected, while with further increase in temperature to $1500{ }^{\circ} \mathrm{C}$ an anomalous grain size decrease was detected. Additionally, a larger fraction of small grains was observed for the sample sintered at $1500^{\circ} \mathrm{C}$. A closer look at the triple points, Fig. 2, revealed the presence of an amorphous phase in all samples. The shape of the triple points is also consistent with the presence of a liquid phase, which is Ti-enriched in comparison with the grain interior. Moreover, some crystalline material was detected inside a fraction of the triple points, which probably crystallized during cooling. ST has a eutectic point at $1440^{\circ} \mathrm{C}$ for Ti-rich compositions, in the range used in this work, and so traces of liquid phase can be expected. The TEM analysis, Fig. 2 (b), confirmed the SEM observations: the shape and contents of the triple points were again consistent with the presence of liquid phase.

In summary, based on SEM and TEM studies, an anomalous grain growth of Ti-rich strontium titanate is reported in this work. The microstructural analysis suggests that the anomaly is related with the presence and amount of a liquid phase, which may not be continuous with increasing sintering temperature. The understanding of this grain growth anomaly may offer a new tool to tailor the microstructure of titanate-based ceramics leading to the design of their dielectric properties.

References

1. M. Baurer, D. Weygand, P. Gumbsch, M.J. Hoffmann, Scripta Materialia 61: 584, 2009 
2. S.-Y. Chung, D. Y. Yoon, S.-J. L. Kang, Acta Materialia 50: 3361, 2002

3. L. Amaral, A. M. R. Senos, P. M. Vilarinho, Microscopy and Microanalysis 14 (S3): 5, 2008

4. A. Tkach, P. M. Vilarinho, A. M. R. Senos, A. L. Kholkin, J. Eur. Ceram. Soc. 25: 2769, 2005

5. L. Amaral, A. M. R. Senos, P. M. Vilarinho, Materials Research Bulletin 44: 263, 2009
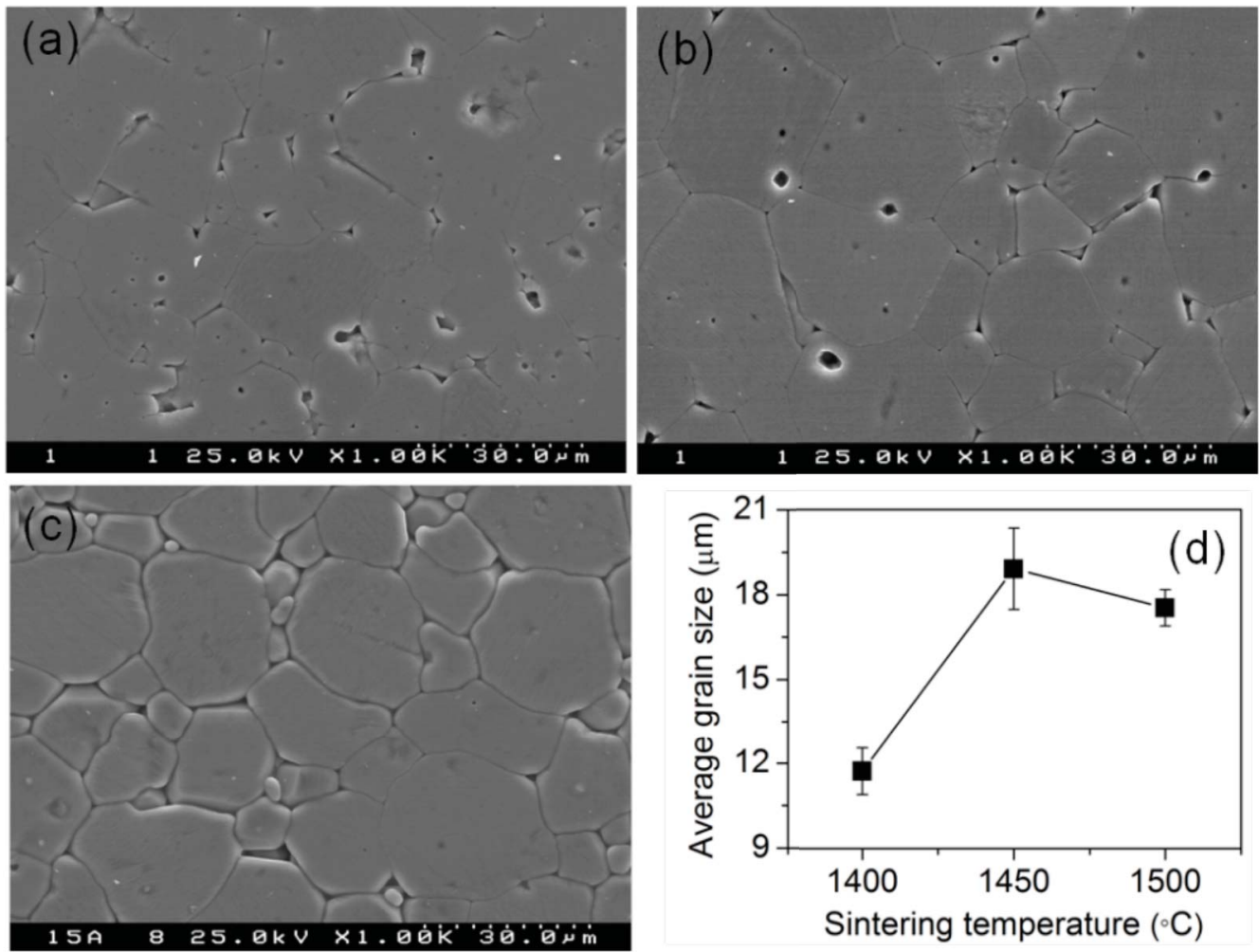

Figure 1. SEM micrographs of the $\mathrm{Sr} / \mathrm{Ti}=0.995$ samples sintered for $2 \mathrm{~h}$ at (a) $1400{ }^{\circ} \mathrm{C}$, (b) $1450{ }^{\circ} \mathrm{C}$ and (c) $1500{ }^{\circ} \mathrm{C}$. (d) Average grain size dependence on the sintering temperature.
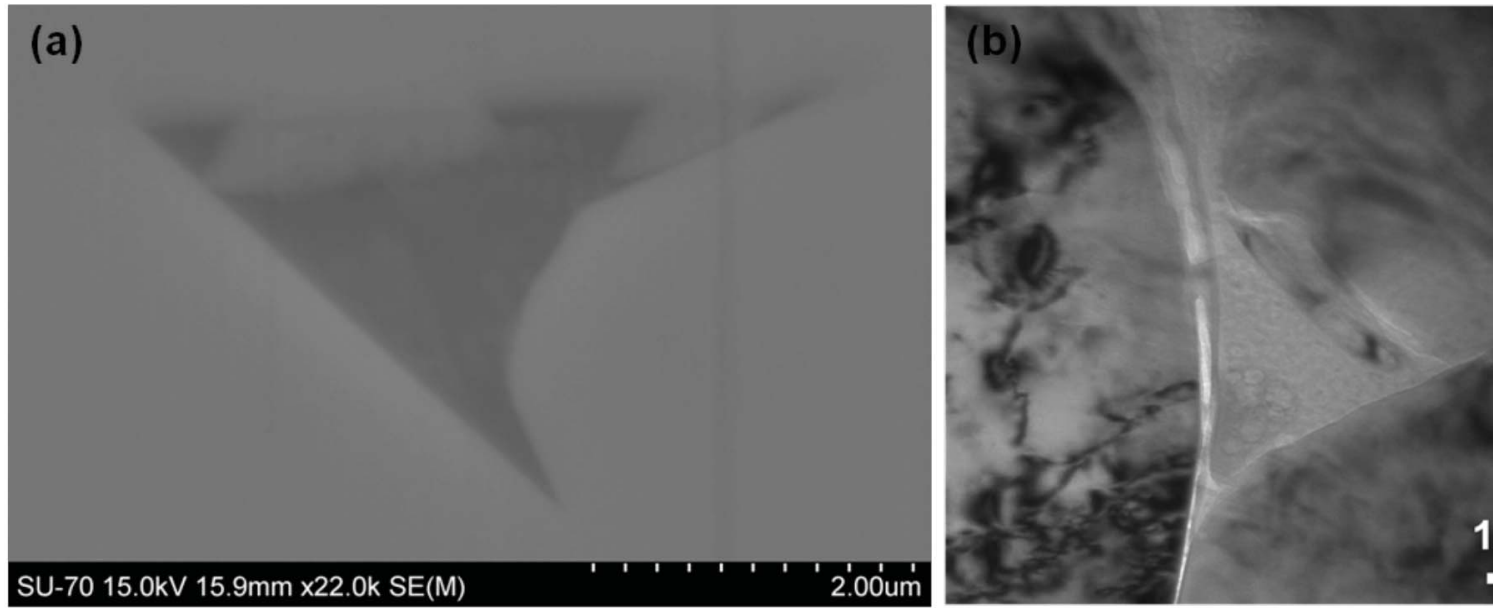

Figure 2. Microstructures of samples sintered for $2 \mathrm{~h}$ at $1450^{\circ} \mathrm{C}$ (a) $(\mathrm{SEM})$ and at $1500^{\circ} \mathrm{C}$ (b) (TEM) showing triple points filled with amorphous phase. 